\title{
Analyses on the Dilemma and Countermeasures about the "Self-development" of Chinese University Students in the New Era from the Perspective of Psychological Development Theory
}

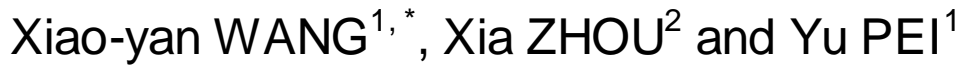 \\ ${ }^{1}$ College of Humanities and Law, Beijing University of Chemical Technology, Beijing city \\ Chaoyang District North Third Ring Road 15, China \\ ${ }^{2}$ Office of Student Affairs, Beijing University of Chemical Technology, Beijing city \\ Chaoyang District North Third Ring Road 15, China
}

Keywords: University students, Self-development, Ego identity, Erikson.

\begin{abstract}
As developing individuals, the university students are faced with a lot of developmental tasks. The "self-development" is the key topic of their development. The research of psychosocial development theory as well as ego identity created by Erik H Erikson provides systematic and theoretical framework to better understand the "self-development" of university students. College-age individuals are in adolescence and young adulthood. Based on the current situation and conspicuous problems of university students" "self-development", this paper quotes relevant point of views from both psychosocial development theory and ego identity, aiming not only to analyze the process and characteristics of how this phenomenon generates, but also to offer guidance for mental health education in related fields.
\end{abstract}

\section{Introduction}

As developing individuals, the university students are faced with a lot of developmental tasks. The "self-development" is the key topic of their development, and it also lays the foundation for other psychological and behavioral processes. Specifically, "ego" refers to the self - recognition of individuals' existential states. Since ancient times, philosophy, science of religion and psychology have regarded "ego" as an important task to research. Today most university students are the after 90's. Facing the problem of judging and reflecting on individual values, the new generation of students, who grow up under the macroscopic background of society transferring rapidly in economic and social developments, need to grasp the direction of self-development, analyze and accept their own states of living. So this situation brings new challenges for adjusting themselves. In the field of psychology, Erik H Erikson's psychosocial development theory provides a systematic perspective for us to understand the central development task and the dilemma about the "self-development" of university students. This theory also provides reference for promoting the psychological health education, whose purpose is to serve for the development of students.

\section{Commentary on Related Theories about "self-development" in Psychosocial Development Theory}

Erik HErikson put forward the personality psychosocial development theory in the middle of the last century. The theory divided the individuals' psychological development into eight stages. Meanwhile, he points out that every stage has its specific development tasks and 
staged contradiction (means psychological crisis). The successful solutions of contradictions in every stage are the preconditions of the sound development of individuals' personality [1].

\section{The Key Points and Core Contradictions of the Psychological Development of University Students}

College-age individuals are in adolescence and young adulthood. About this stage, Erik $\mathrm{H}$ Erikson discusses the two principal themes in his theory: the first is the discussion about the core contradiction in adolescence, which means the contradiction between ego identity and role confusion; the other is the discussion about the contradiction in young adulthood, which refers to the conflict between intimacy and loneliness. The former focuses on the theme of "ego" in individual development, and the latter focuses more on the theme of "relationship" between individuals and other people [2].

According to Erik H Erikson, individuals need to deal with the tasks of every development stages in their whole life. But prior stage lays foundation for the next stage. The successful solution of the prior crisis makes preparation for the development of the next stage; otherwise it would lead to a bigger chaos. So we can see that for university students, the stable development of the theme of "ego" is the precondition of the theme of "relationship", especially intimate relationships. So as for the two themes of "ego identity" and "intimate relationship", the education and development of the theme of "ego" is more urgent, and it also lays foundation for the sound development of the following stages such as intimate relationships.

\section{The Concept of Ego Identity and the Developmental States of Ego Identity}

According to Erik H Erikson's theory, during the development of ego identity, if the development is smooth, an individual would show a clear ego concept and a certain pursuit, which means he or she has established ego identity [1]. On the contrary, if the development doesn't work smoothly, the individual would lack life goals and be confused, leading to identity diffusion and negative identity development. Individuals under the state of diffusion lack the ability of self-discovery, and have no clear self-recognitions, nor do they know what kinds of people they are or want to be. Usually they can't do self-determination. They either give the decision-making power to others (such as parents), or listen to others, avoid contradictions and postpone their decisions. So they can't choose the right life roles that adapt social environment. Under negative state, the situations could be more serious; the individuals could become characters that are not recognized by our society or anti-social, such as adolescents' unorthodox behaviors, irrational challenges to rules, crimes and drug takings.

\section{The Theoretical Advances in the Development State of Ego Identity}

Based on the theories of Erik H Erikson and solid evidence, Marcia develops the state model of ego identity. She puts forwards four states of ego identity, including identity achievement, identity foreclosure, identity diffusion and identity moratorium. Identity achievement refers to that through explorations, individuals think over various problems about themselves, set the goals of self- investment, and make firm and positive self-investment toward specific goals, faiths and values; Identity foreclosure refers to that individuals make premature investment without experiencing specific explorations [1,3]. This kind of investment is unconscious, and is based on the expectations or suggestions of parents or authorities. Identity moratorium refers to the phenomenon that individuals explore various options positively, but they haven't made higher investment towards specific goals, values and ideology. Identity diffusion refers to the phenomenon that individuals haven't contemplated about or explored any question related to 
themselves. So they haven't got the experience that could help them to solve the current crisis. It is easy for them to slip into a state, in which they have no certain values and goals, and they can't get into clear social roles. By longitudinal studies, Cramer has found that in the stage from late adolescence to early adolescence, individuals transform more universally from the states of identity foreclosure and identity diffusion to the states of identity achievement and identity moratorium $[3,4]$.

\section{Understand the Dilemma about the "self-development" of University Students from the Perspective of Psychosocial Development Theory}

The Perspective of Psychosocial Development Theory and its following theoretical perspectives provide us with thinking directions to understand the dilemma about the "self-development" of university students. If we analyze the current dilemma about the "Self-development" of University Students in this way, we could improve the quality of education in related fields, and serve better for the growth of students.

\section{The Establishment and Integration of Ego Identity Is the Core of the "self-development" in Undergraduate Phase}

According to Erik H Erikson's theory, people confront important issues and crises constantly in their whole life, and these crises become the important motive force for the individuals' development. Meanwhile, during the process of solving the crises, the force could improve the weaknesses of the previous crises' solutions. University students are at the transitory stage from late adolescence to early adulthood. Their external physical fitness is relatively mature. Their cognitive competence and logical judgment are relatively thorough. The distance between them and society is reducing. But they still live in institutional lag phase permitted by our society. So they have relatively adequate buffer time for self-development, and can be allowed to do more explorations about their ideals and choices. But because they haven't come upon the stage and lack practical experience, they are faced with more confusions and contradictions. Under this kind of open and free circumstance, the establishment and integration of ego identity confront a more urgent task.

\section{Survey the Dilemma about the "Self-development" of University Students from the Theoretical Perspective of the Development of Ego Identity}

When we are able to notice the setbacks and progress of university students during the process of establishing ego identity, the enormous impacts and psychological fluctuations they face become understandable. Their confusions in life and strong fluctuations of self-belief are the only way in the process of self-request and self-assertion. But if this kind of state exists for a long time with intense negative emotions, the reason maybe that they haven't tried self-exploration, in other words, they are in the state of identity diffusion. Or they are hindered or restricted in the process of establishing and integrating ego identity so that they get into the key stage or a bottleneck period, which means the state of identity moratorium. The university students possess some characteristics including lacks of interests and happiness, externalization of motive and excessive utility, and this phenomenon is causal. The first reason is that some university students lack a clear self-recognition. They are doing self-explorations but they haven't achieved the stage of self-identity. So it is hard for them to find their interests, and their interests are changing all the time. The other reason is that many students regard the standards which their parents or the public approve of as their own standards [5]. Without 
experiencing self-exploration, the standards enter their self-system directly without personal psychological processing. So they get into pragmatic life prematurely and stick to the external goals, which is at the stage of identity foreclosure. For a long time, students depend on their will in order to stick to their goals. Therefore they lack the support of internal strength. So it is hard for individuals to gain satisfaction and joviality on an emotional level.

\section{The New Characteristics of Chinese College Students in the Process of Ego Identity Development in Recent Years}

Psychosocial development theory stresses that the theme of "ego" is the core content in the development of adolescence, which has a special mission to connect childhood and adult stage. In terms of childhood, individuals relatively passively accept more influence from parents and families than themselves. Parents and families play a more important role in the process of individual development. However, after moving through adolescence, individual's subjective initiative and self role begin to come into play. In this case, individual could enter adulthood smoothly after going through the integration of identity. But the problem is that China has a special state of development in both politics and economy, leading to a great shift in the structure and function of families, which hinders the development of identity.

\section{The New Thinking Towards the Promoting Function of China's College Mental Health Education in the College Students' Ego Development}

Promoting students' all-round development, improving their social adaptation ability and serving the society are the important missions of higher education. As an important carrier serving for students' growth, college mental health education carries a significant mission in helping student overcome difficulties during ego development, accelerate the pace of ego development and improve ego function.

\section{Promoting Students to Overcome Difficulties and Develop Themselves is the Important Kernel of Mental Health Education}

The ultimate goal of education is to make all the individuals being themselves. After entering adolescence, teenagers' subjective initiative and self role exert more influence than that from parents and families. The schooleducation of university stage could play a more important role in the process of individual's psychological maturity and ego development. Meanwhile, Chinese universities generally practice a system of accommodation so that college students are separated from their parents geographically. So the need for students to perceive more self conflicts and self developments is more urgent. However, nowadays, general professional education and the first class education are more focused on satisfying the demand of knowledge, skills and the development of professional ability rather than the mental development of individuals. And because of the restriction on both class hour and student capacity, the first class education of liberal education and cultural quality only play a limited role. So it's very necessary to provide more services and education about the theme of self-development in the field of mental health education. Moreover, the improvement of ego function and the achievement of identity are the premise for them to complete social mission and pursue ideals. Otherwise, it can easily lead to an inner pain experience and the psychological risk events on campus. 


\section{Helping Students Define the Boundary and Emphasize Ego Function is the Focus of Mental Health Education}

From common problem of college students' development dilemma, we could find that many of them don't have a clear border in their mind about ego maturity and self-development. Facing many big issues in their lives, they mostly choose to depend on the authority decision from parents and teachers or escape problems with a numb attitude. They have a weak awareness of self-responsibility, or even don't have this awareness. In the current situation of Chinese families and schools, most parents and teachers are willing even habitual to cross personal boundaries, intervening excessively or even replacing the students' role in their growing process. They disrupt the formation of a clear individual border and destroy the improvement of ego function. Therefore, helping college students define the individual boundary, set clear goal of self-development and become who they really are should be the focus of mental health education rather than imitating or yielding to others. The concrete practices to help college students improve ego function could be facilitating the reaching of their autonomy, strengthening the awareness and ability of self-responsibility, and having active reflection and reasonable treatment towards the border incursion in families or schools.

\section{Enriching Students' Psychological Structure and Promoting Self-exploration Are the Key Breakthrough Points of Mental health Education}

It's not a overnight process for college students to confirm their self-worth and have a self-development but constant enrichment and development of their mental structure and content. While only the abundant or impressive experience could help individuals to adapt rules, reality and future. In this process, whether the education is in mental health, morality or ideology, teachers should avoid empty preaching and infusing but focus on the occurrence of students' mental activities and the process of arousing emotional experience. [1,5].

\section{Achieving a Harmonious Development Between Cognition and Ego is the Final Placement of Mental Health Education}

The core goal of higher education is to cultivate the high-quality talents. And the coordinated development between individual cognitive ability and ego function could help individuals to go further and higher, achieving the goal that higher education could cultivate top talents. We can imagine that students who have a rapid development of cognitive ability but poor ego function must be the people who lack for happiness and have violent mood swings. They may be successful in a short-term but must have the problem of aftereffect inadequacy, which could not adapt to the purpose of higher education. With the tendency that higher education stress students' development of knowledge, skills and wisdom, mental health education should bring the developmental idea to teachers, students and educational process, attracting more educational powers to pay attention to students' self-growth and self-improvement, helping students to find their inner interest and instinct, increasing their pleasure of study and development, promoting the balanced development between cognitive function and ego function. 


\section{Creating A Psychological Atmosphere That School Is A Place Full of the Sense of Belonging Is the Macro Direction of the Psychological Health Education}

We should create an atmosphere full of love and hope in our campus. Another side of ego identity establishment is "one sense" or "joint sense". In students' main living places, such as class, dormitory, club and so on, if they can find the sense of belonging, it will certainly cause the lack of one sense and joint sense. Moreover, although self-exploration and self-development is an individuation, individual couldn't form an objective cognition of "ego" and deal with the difficulties in the self-exploration without social reference system and social support resources. So, educational powers could focus on guiding students to build positive interpersonal atmosphere within dormitory members, class members, community members, student organization members and teachers, making school, class, club, student organization, dormitory contagious places where students could find sense of belonging and calling.

\section{References}

[1] HU Jin-lian, A Comparative Research of Pro-social Behavior of University Students in the Social Transformation Period, Academic Exploration. 3(2015)77-81.

[2] WANG Shu-qing, CHEN Hui-chang, SHI Meng, Adolescent Ego Identity Status Development and Its Relations with Parenting Authoritativeness and Identity Style, Psychological Development and Education. 24(2008)65-72.

[3] M. Syed, I. Seiffge-Krenke, Personality development from adolescence to emerging adulthood:linking trajectories of ego development to the family context and identity formation, Journal of Personality and Social Psychology. 2( 2013)371-384.

[4] H. Bang, D. Montgomery, Wisdom and ego-identity for Korean and American late adolescents, Cross-Cultural Psychol. 5 (2013)807-831.

[5] HUANG Hua-Hua, LIU Shao-Ying, XU Fen, Relationship between ego identity and social adjustment in college students, Chinese Mental Health Journal. 28(2014)70-74. 